\title{
Welcome to the Ipad generation
}

\author{
David Wong • Antonia Joussen
}

Published online: 23 December 2010

(C) The Author(s) 2010. This article is published with open access at Springerlink.com

To write what is worth publishing, to find honest people to publish it, and to get sensible people to read it, are the three great difficulties in being an author.

$$
\text { Charles Caleb Colton (1780-1832) }
$$

Graefe's Archive has a long tradition that is tightly connected with the history of German ophthalmology and ophthalmology at the Charite in Berlin. In 1853, Albrecht von Graefes was appointed teacher of ophthalmology at the university of Berlin and the Charité; in 1858, he became an Extraordinary Professor, and in 1866 an Ordinary Professor. Graefe contributed greatly to ophthalmological science, particularly by the establishment in 1855 of his Archiv für Ophthalmologie, in which Carl Ferdinand von Arlt and Franciscus Donders collaborated. Graefe's Archives is now returning to the Charité in Berlin and again will profit from a collaborative editorship - nowadays "worldwide" shared between Berlin and Hong Kong. With this, we hope to promote the excellence of the journal both in Europe and abroad.

When reflecting that Gutenberg invented the printing press in 1445, he changed the lives of people in Europe. For

\footnotetext{
A. Joussen

Department of Ophthalmology,

Charité, University Medicine Berlin,

Virchowklinikum (CVK),

Augustenburger Platz 1,

13353 Berlin

Klinikum Steglitz (CBF)

Hindenburgdamm 30

12200 Berlin, Germany

D. Wong $(\square)$

The Eye Institute

LKS Faculty of Medicine,

The University of Hong Kong,

Hong Kong, Hong Kong

e-mail: shdwong@hku.hk
}

the first time, books became affordable and education was no longer the preserve of the wealthy. The spread of knowledge eventually fueled the Renaissance.

The advent of the Internet arguably has had an even greater impact on the way we live today. Like cheap books, the Internet has made information more accessible. In fact, many doctors and scientists receive complimentary online journals via their hospitals and universities. As a result, libraries are stopping subscriptions to paper copies. This in turn threatens the profitability of publishing. The lag time in publication means that many of us are reading the epub abstracts long before they appear in print, and when we do read, we are increasingly likely to do so using an Ipad or some other smart portable devices.

The ease of using databases such as PubMed and Medline means that we are much more exhaustive in our literature searches. References and bibliographies are becoming longer. This has the effect of increasing citation, which in turn raises the impact factor of most medical journals. In fact, there are so many references that it has become "acceptable" to selective quote a chosen few. Even as little as 20 years ago, this would have been frowned upon as being unscholarly. Like carrying out Google searches, few of us these days are interested beyond the top 20 results.

Some things, however, remain the same. When it comes to journal submission, the top ranking journal always attracts the best articles. The best articles are quoted often and the ranking of that goes up even higher. Quite simply, the rich gets richer. Under the editorship of Prof. Bernd Kirchhof, the impact factor of the journal has increased from 1.279 to 2.102 and the ranking from 21 to 19 over the last 6 years. This is due to one man's hard work, dedication, and a keen editorial sense that could differentiate the newsworthy from the mundane. The new editors are 
fortunate to inherit such momentum and are at the same time daunted by the challenge.

Graefe's is the official journal of the following societies: Club Jules Gonin, The German Society of Ophthalmology, and the International Society of Ocular Trauma, and has a fine and long tradition. The editors will strive to ensure the articles selected are not only scientifically rigorous but also succinct, interesting, and clinically significant. We wish to broaden the appeal to the readership by ensuring that epub-first articles are readily accessible. Having one editor in Europe and one in Hong Kong, we hope to promote the journal's excellence both at home and abroad. One aim is to make available the abstracts translated into Chinese on-line. Most importantly, today's researchers belong to the Ipad generation and when they access ophthalmic literature online, we will make sure they find and read articles from Graefe's.

We look forward to working with the editorial office in Glasgow, the publisher in Heidelberg, and an international editorial board. We wish the readership a happy and successful 2011.

Open Access This article is distributed under the terms of the Creative Commons Attribution Noncommercial License which permits any noncommercial use, distribution, and reproduction in any medium, provided the original author(s) and source are credited. 